\title{
David Oliver: Fighting phantom policies in hospitals
}

\author{
David Oliver consultant in geriatrics and acute general medicine
}

Berkshire

Much has been written about the informal "hidden curriculum" in clinical training that can influence our behaviours, perceptions, and values. ${ }^{12}$ Hospital medicine has a parallel problem of hidden or "phantom" policies, which aren't formally written but become accepted custom and practice.

I'm aware of this from working in older people's acute care, but readers in other specialties will have their own bugbears. This is no exhaustive list, but I'll give some examples.

Contrary to popular belief, patients discharging themselves against medical advice (for whatever reason) can still be offered transport and medication. And people who aren't self discharging shouldn't have to wait for medicine to be dispensed before they leave the ward if someone can pick it up later or it can be sent after them.

Despite a regulatory impetus for patients to be reviewed by a senior clinician, ${ }^{3}$ it's not the case on clinical grounds that every patient, however stable, must be reviewed by a consultant every day, nor that any patient about to go home must first be blessed by a doctor. Criterion based discharge led by a nurse or therapist could often be an alternative. ${ }^{45}$

When an acutely admitted patient's primary presenting problem naturally sits under vascular, orthopaedic, urological, or general surgery but may not need an urgent operation, disputes can occur between surgical and medical teams over who has continuing responsibility for the patient, even when agreed rules and protocols are in place. Urban myths about what grade of doctor is authorised to accept or reject a patient from the caseload are not helped by the transient nature of training rotations or a lack of collegiality among consultants.

Doctors and occupational therapists routinely discuss care with patients' families by phone as a necessary part of care and communication, but I've too often seen nurses saying that this isn't allowed because of confidentiality and data protection. We'd do a worse job for some patients and families if we didn't use the phone to discuss care. The Data Protection Act and regulations don't forbid such calls, and written hospital policies and training recommend caution regarding patient consent or caller identity, not blanket bans. ${ }^{67}$
Although any clinical or social care professional is authorised by law to assess and document decision specific mental capacity, ${ }^{8}$ too often arbitrary local customs suggest that only specific professionals (such as consultants, including psychiatrists) may document it in a way acceptable to other teams, who could often complete assessments themselves and are in effect operating their own arbitrary policies.

Ward multidisciplinary teams add great value to assessment and care, and this is clearly evidenced. ${ }^{9}$ But it doesn't follow, as a matter of routine practice, that all patients must wait for a formal occupational therapy or physiotherapy assessment (including stairs) before they can go home. If it's uncontentious to other members of the ward team that patients can care for themselves or require minimal assistance, this should let the therapists focus on more complex assessments where they add the most value.

There's a parallel risk of "supply led demand" and of potential deskilling and learnt helplessness among ward teams if every patient whose diabetes, depression, delirium, or dementia accompanies acute illness - or every dying patient—is automatically referred to liaison psychiatry or specialist nurse practitioners. These teams have tremendous expertise, but competent generalists should manage the basics and not make "referral for all" the new norm.

There's so much more we could choose to do differently. The current focus on quality improvement and implementation science gives us impetus and opportunities. And, with system pressures and staffing gaps, necessity is the mother of invention. The key thing is to test, refine, and evaluate changes to service models as we go.

One of many illustrative examples was the move described by the Health Foundation in flow-cost-quality studies in Sheffield and Warwick. This shifted the focus away from "assess to discharge"-where no one could go home or be referred on without a range of functional assessments in hospital-towards "discharge to assess," where patients were sent home with support much earlier for ongoing assessments at home. ${ }^{111}$

The results were impressive: the change has been embedded and since adopted by other sites. ${ }^{12}$ This shows what can be done 
if we don't let "phantom" policies stalk our wards. Let's see them, name them, and exorcise them.

Competing interests: See www.bmj.com/about-bmj/freelance-contributors.

Provenance and peer review: Commissioned; not externally peer reviewed.

Walsh K. The hidden curriculum. BMJ 2005;331:105610.1136/bmj.331.7524.1056.

2 Lempp $\mathrm{H}$, Seale $\mathrm{C}$. The hidden curriculum in undergraduate medical education: qualitative study of medical students' perceptions of teaching. BMJ 2004;329:770-3.

$10.1136 / \mathrm{bmj} .329 .7469 .77015459051$

3 Oliver D. David Oliver: Seven day service standards in NHS hospitals: thorny problem or blooming success?BMJ 2017;359:55552. 10.1136/bmj.j5552 29208735

4 Ubbink DT, Tump E, Koenders JA, Kleiterp S, Goslings JC, Brölmann FE. Which reasons do doctors, nurses, and patients have for hospital discharge? A mixed-methods study PLoS One 2014:9:e91333. https://www.ncbi.nlm.nih.gov/pmc/articles/PMC3953385/. 10.1371/journal.pone.009133324625666

5 NHS Interim Management and Support. Effective approaches in urgent and emergency care-paper 3: whole system priorities for the discharge of frail older people from hospital care. 2012. https://www.england.nhs.uk/wp-content/uploads/2013/08/dis-old-people.pdf.
6 Salisbury NHS Foundation Trust. Telephone guidance-how to handle incoming calls. Sep 2014. https://www.salisbury.nhs.uk/AboutUs/OurPoliciesAndProcudures/Documents/ DPC\%20D\%20Policy\%20Appendix\%20H\%20V2.0.pdf.

7 Poole Hospital NHS Foundation Trust. Data protection and information sharing: information governance ("IG") policy. Jan 2018. https://www.poole.nhs.uk/pdf/IG.P01\%20-\%20Data\% 20Protection\%20and\%20Information\%20Sharing\%20Policy\%20(v3.2\%20Jan\%202018) .pdf.

8 NHS. Mental Capacity Act. 10 Jan 2018. https://www.nhs.uk/conditions/social-care-andsupport-guide/making-decisions-for-someone-else/mental-capacity-act/.

9 Ellis G, Gardner M, Tsiachristas A, etal . Comprehensive geriatric assessment for older adults admitted to hospital. Cochrane Database Syst Rev 2017;9:CD006211. https://www. cochrane.org/CD006211/EPOC_comprehensive-geriatric-assessment-older-adultsadmitted-hospital. 10.1002/14651858.CD006211.pub3 28898390

10 Health Foundation. Flow cost quality. https://www.health.org.uk/funding-and-partnerships/ programmes/flow-cost-quality.

11 Silvester KM, Mohammed MA, Harriman P, Girolami A, Downes TW. Timely care for frail older people referred to hospital improves efficiency and reduces mortality without the need for extra resources. Age Ageing 2014;43:472-7. http://ageing.oxfordjournals.org/ content/43/4/472.full.pdfdoi:10.1093/ageing/aft170. 10.1093/ageing/aft170 24222658

12 Thomas M. Acute frailty on the AMU: the challenges. 2018. https://www.acutemedicine. org.uk/wp-content/uploads/2018/06/Acute-Frailty-Network.pdf.

Published by the BMJ Publishing Group Limited. For permission to use (where not already granted under a licence) please go to http://group.bmj.com/group/rights-licensing/ permissions 